\title{
A METHOD FOR EVALUATION OF NON-UNIFORM RADIANT-CONVECTIVE LOAD ON HUMAN BODY DURING MENTAL WORK
}

\author{
Lenka Prokšová Zuská*, Michal KabRhel \\ Czech Technical University in Prague, Faculty of Civil Engineering, Department of Microenvironmental and \\ Building Services Engineering, Thakurova 7, 166 29 Prague, Czech Republic \\ * corresponding author: lenka.zuska@fsv.cvut.cz
}

\begin{abstract}
The objective of this study was to develop a documentation for the amendment of the microclimatic part of the Czech Government Regulation, particularly in a non-uniform radiantconvective load evaluation. Changes in regulation were made based on experimental data obtained on a group of experimental individuals in a climatic chamber. One of the objectives of the climatic chamber experiments was to evaluate whether there was a possibility to use an alternative method, which utilizes a new value — stereotemperature, for the assessment.

A group of 24 women was exposed to a non-uniform radiant-convective load in a climatic chamber for 1 hour during their computer work. Measurements were divided according to the globe temperature into 3 stages. The physical parameters of air were continuously measured: the air temperature, globe temperature, air velocity, radiant temperature, relative humidity, stereotemperature and physiological parameters. Thermal sensations of experimental subjects were expressed in the seven-point scale according to EN ISO 7730 .

The thermal sensation correlated very well with the difference of stereotemperature and the globe temperature. The stereotemperature correlated very well with the radiant temperature. In this work, the composed equations were used to develop the limit values for the thermal stress evaluation in the uniform and non-uniform thermal environment at workplaces. It is possible to determine how the body of an exposed person perceives the non-uniform climatic conditions in the indoor environment, by adding the stereotemperature to government regulations.
\end{abstract}

KEYWORDS: indoor environment; non-uniformity thermal load; thermal conditions at workplaces; stereotemperature; stereothermometer.

\section{INTRODUCTION}

A non-uniformity of a heat-humidity microclimate can be observed both in residential buildings as well as in workplaces. It occurs in hot workshops and industrial facilities (e.g. in steel mills and glass factories), where the workers are exposed to an excessive thermal radiation from a single direction. A building with light external cladding (office buildings) is another example. Large windows are a source of thermal radiation in summer (but also in spring and autumn) and excessive cold radiation in winter. The unevenness in the area might be caused by poorly adjusted air conditioning units, air heating or cooling systems, heating surfaces and the location of radiators.

People perceive heat or cold of the environment through thermoreceptors located in the skin, hypothalamus and core body [1]. Thermoreceptors perceive ambient temperatures in the tissue, and send signals to the brain in the form of a heat feeling [2]. An environment that is too hot or cold causes unpleasant reactions of the human body (e.g. sweating, cold hands and ankles) and therefore a local discomfort. The thermal balance of the human body is provided through human skin [3]. As it is well known, the human thermal comfort is conditioned by the thermal equilibrium. This is achieved when the body produces the same heat as the vicinity of the body takes away.

Heat-humidity conditions are physical factors that influence the subjective feeling of the person's thermal comfort and their job performance [4]. The user satisfaction with the artificially created environment in a building is, therefore, increasingly important from the economical point of view. Besides the investment and consequently operating costs of engineering systems of the environment, the importance is also placed on the relationship between the user satisfaction with the indoor environment in buildings and job performance. If people are not satisfied with the given environment, then the job performance decreases and the labour costs increase. This may play a more important role than increased operating costs to improve the microclimate parameters and vice versa [5].

The basic document for the evaluation of a nonuniformity radiant-convective load in the European Community is EN ISO 7730:2005 [6]. The document is based on the prediction of a human thermal sensation, calculated by the predicted mean vote (PMV) and predicted percentage of dissatisfied (PPD), the people which will be dissatisfied with the environment 


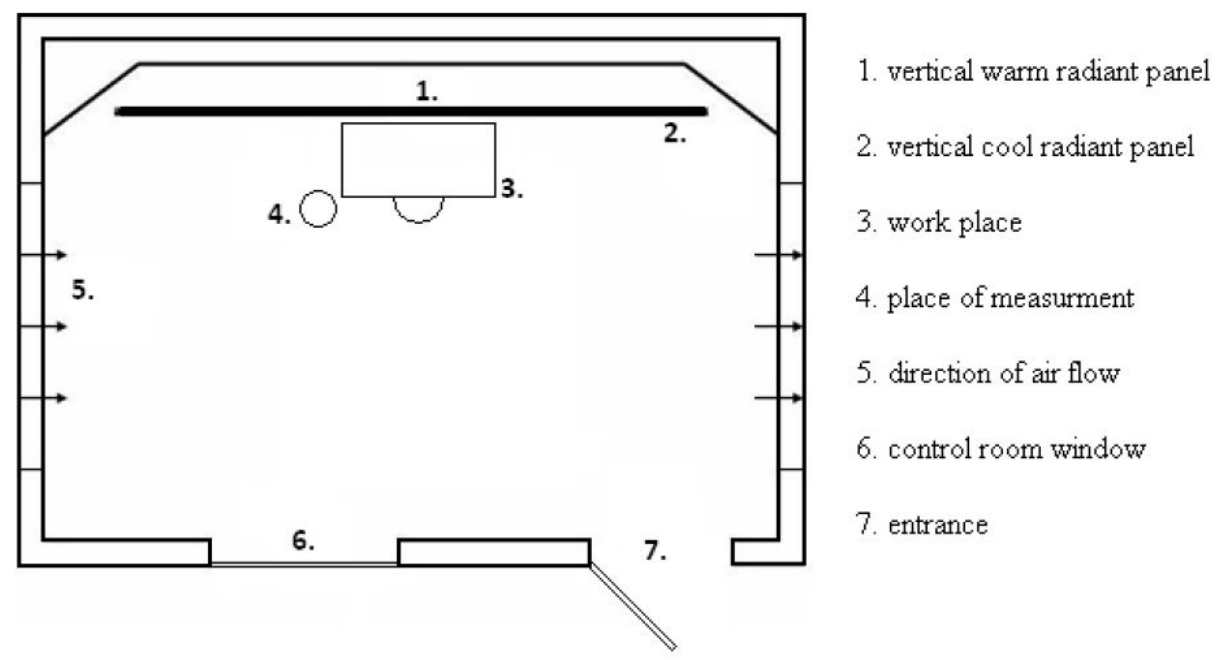

Figure 1. The climatic chamber [15].

within the meaning of excessive heat or cold. The currently used PMV model was developed in coherent and steady-state experimental conditions [7]. Humphreys and Nicol [8] described the shortcomings of the PPD and PMV indices specified in EN ISO 7730. It is a set of errors, such as errors in the calibration in humidity measurement, determining the values for metabolism or the error in the clothes insulation measurement. Furthermore, it was found that the PMV and PPD can be seriously misleading when used to predict the mean comfort votes of a group of people in everyday conditions in buildings, particularly in warm environments. Residents of buildings are able to adapt to a much wider range of conditions and accept a higher indoor temperature than it is predicted by the PMV/PPD model [8].

The issue of a non-uniform thermal load inside buildings has not been adequately solved in the past years in the Czech legislation. The means of evaluating the radiant temperature asymmetry (RTA) has been supplemented by an alternative evaluation of uneven components of the environment. Therefore, the value of stereotemperature $t_{\text {stereo }}\left(\right.$ or $t_{\mathrm{st}}$ ), for the horizontal or vertical non-uniformity of the indoor environment in the workplace, was introduced in the hygiene regulation in the Government Regulation in Czech Republic No. 93/2012 Coll. [9].

The aim of the study was to determine the response of the selected physiological indicators and feelings of the subjects during mental work in a non-uniform heat load under experimental conditions in a climatic chamber. Another objective was to verify that the value of $\Delta\left(t_{\text {stereo }}-t_{\mathrm{g}}\right)$ characterizes the non-uniformities of the thermal environment as well as the value of the radiant temperature asymmetry RTA obtained as $\Delta\left(t_{\mathrm{rA}}-t_{\mathrm{rB}}\right)$. This work also includes a local discomfort evaluation by objective methods for the evaluation of microclimatic conditions.

\section{MATERIALS AND METHODS}

The experiments took place in a climatic chamber of National Reference Laboratory for Measuring and Evaluation Thermal Conditions at the Institute of Public Health in Ostrava. The experiment included measuring the physical factors of the thermal environment, physiological response measurement and feelings of subjects' observations and effect of mental performance.

The climatic chamber has an internal space $2 \times 3 \times$ $2 \mathrm{~m}$, (Figure 1). The conditioned air is supplied to the chamber from an engine room through a hole with dimensions $1 \times 1 \mathrm{~m}$ in the direction of the long axis of the chamber. The chamber allows to set the air velocity $\left(v_{\mathrm{a}}\right)$ in the range from 0.2 up to $2 \mathrm{~m} \mathrm{~s}^{-1}$, the air temperature $\left(t_{\mathrm{a}}\right)$ in the range from 0 up to $60^{\circ} \mathrm{C}$ and the relative humidity $(R H)$ in dependence on the air temperature in the range from 30 up to $90 \%$. The intensity of the unilateral radiation has its maximum at $200 \mathrm{~W} \mathrm{~m}^{-2}$.

The measurements were divided into three stages (SI to SIII) according to the globe temperature $\left(t_{\mathrm{g}}\right)$ subsequently:

- SI: $t_{\mathrm{g}}=19^{\circ} \mathrm{C}$;

- SII: $t_{\mathrm{g}}=22^{\circ} \mathrm{C}$;

- SIII: $t_{\mathrm{g}}=25^{\circ} \mathrm{C}$.

The differences between the radiant temperature measured from the direction of the radiation $\left(t_{\mathrm{rA}}\right)$ and the globe temperature $\left(t_{\mathrm{g}}\right)$ in each stage are shown in Table 1. The radiation intensity $(I)$ ranged from -97 to $+153 \mathrm{~W} \mathrm{~m}^{-2}$ in all stages. The air velocity was set to $v_{\mathrm{a}}=0.25 \mathrm{~m} \mathrm{~s}^{-1}$. The relative humidity fluctuated in the physiological range between $30-70 \%$. The thermal conditions were chosen to be the optimal conditions for a uniform thermal environment of the experimental subjects (ES). 


\begin{tabular}{|c|c|c|c|c|c|c|c|c|c|}
\hline \multicolumn{3}{|c|}{ Stage I (SI) } & \multicolumn{3}{|c|}{ Stage II (SII) } & \multicolumn{3}{|c|}{ Stage III (SIII) } & \multirow{2}{*}{ 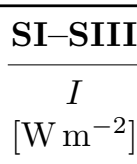 } \\
\hline $\begin{array}{c}t_{\mathrm{g}} \\
{\left[{ }^{\circ} \mathrm{C}\right]}\end{array}$ & $\begin{array}{l}t_{\mathrm{rA}} \\
{\left[{ }^{\circ} \mathrm{C}\right]}\end{array}$ & $\begin{array}{c}t_{\mathrm{rA}}-t_{\mathrm{g}} \\
{\left[{ }^{\circ} \mathrm{C}\right]}\end{array}$ & $\begin{array}{c}t_{\mathrm{g}} \\
{\left[{ }^{\circ} \mathrm{C}\right]}\end{array}$ & $\begin{array}{l}t_{\mathrm{rA}} \\
{\left[{ }^{\circ} \mathrm{C}\right]}\end{array}$ & $\begin{array}{c}t_{\mathrm{rA}}-t_{\mathrm{g}} \\
{\left[{ }^{\circ} \mathrm{C}\right]}\end{array}$ & $\begin{array}{c}t_{\mathrm{g}} \\
{\left[{ }^{\circ} \mathrm{C}\right]}\end{array}$ & $\begin{array}{l}t_{\mathrm{rA}} \\
{\left[{ }^{\circ} \mathrm{C}\right]}\end{array}$ & $\begin{array}{c}t_{\mathrm{rA}}-t_{\mathrm{g}} \\
{\left[{ }^{\circ} \mathrm{C}\right]}\end{array}$ & \\
\hline \multirow{8}{*}{19} & 16 & -3 & \multirow{8}{*}{22} & 16 & -6 & \multirow{8}{*}{25} & 16 & -9 & -97 \\
\hline & 19 & \pm 0 & & 19 & -3 & & 19 & -6 & -80 \\
\hline & 22 & 3 & & 22 & \pm 0 & & 22 & -3 & -62 \\
\hline & 25 & 6 & & 25 & 3 & & 25 & \pm 0 & -44 \\
\hline & 32 & 13 & & 32 & 10 & & 32 & 7 & \pm 0 \\
\hline & 40 & 21 & & 40 & 18 & & 40 & 15 & 55 \\
\hline & 46 & 27 & & 46 & 24 & & 46 & 21 & 99 \\
\hline & 53 & 34 & & 53 & 31 & & 53 & 28 & 153 \\
\hline
\end{tabular}

TABLE 1. The summary of the microclimatic conditions during the experiments [15].

The air is conditioned in a nearby engine room. The automatic regulation is controlled straight from the control room of the chamber. The physical and physiological parameters of subjects are continuously registered within the experiment and stored in a computer memory. A correlation and regression analysis was used for the statistical evaluation $(\alpha=5 \%)$. The processing was done in Stata v. 9 [10].

The experiments were done on a group of 24 women aged 20-23 years (ES), students of the Medical Faculty at the University of Ostrava. Experimental subjects were dressed in a simple suit. Depending on $t_{\mathrm{g}}(19-$ $25^{\circ} \mathrm{C}$ ), a clothing insulation was $1.0,0.75$ and 0.5 clo. The clothing insulation was set by ISO 9920 [1]. The experimental subjects were familiar with the experiment 12 and have been pre-trained for the mental performance for computer tasks in optimal conditions (without a non-uniform radiant-convective load) to achieve a stable performance. The mental performance evaluation is a part of a different work [13. The experimental subjects were exposed to experimental conditions for one hour. After entering the chamber, the ES first adapted to the experimental conditions for 20 minutes by sitting at the computer. The ES faced the radiant panel in all stages of the experiment. Physical conditions were continuously measured in the height of $110 \mathrm{~cm}$ above the floor, next to the head of the ES [14. Other necessary boundary conditions of the experiment are available in 15, 16.

\subsection{Radiant Temperature Asymmetry MeAsurement}

The name „radiant temperature asymmetry“ (Radiant Temperature Asymmetry, RTA) was suggested by Fanger, Olesen et al. [2]. Brüel and Kjaer - Indoor Climate Analyzer type 1213 is still used to determine the RTA. The same device was also used in the climatic chamber.

The EN ISO 7726 [14] mentions that RTA is indicated as $\Delta t_{\mathrm{pr}}$ and is defined as the difference between the plane radiant temperatures $t_{\mathrm{pr} 1}, t_{\mathrm{pr} 2}$ (corresponding to the above $\left.t_{\mathrm{rA}}, t_{\mathrm{rB}}\right)$ of two opposite sides of a small plane element:

$$
\Delta t_{\mathrm{pr}}=t_{\mathrm{pr} 1}-t_{\mathrm{pr} 2}[\mathrm{~K}]
$$

Since the asymmetry of the radiant temperature is related to the small planar element, its value depends on its orientation. The orientation can be determined in certain situations, such as a ceiling and floor asymmetry. However, if the direction is not specified, the radiant asymmetry should be related to the orientation giving the maximum values [14].

\subsection{Globe Stereothermometer MeAsurement}

Measured physical parameters were $t_{\mathrm{a}}, v_{\mathrm{a}}$, the relative humidity and radiant temperature measured in the direction of the radiation $t_{\mathrm{rA}}$ and on the opposite side $t_{\mathrm{rB}}$. Those values were measured by Indoor Climate Analyzer type 1213, Brüel and Kjaer.

For a radiant temperature asymmetry measurement (RTA), another alternative Czech patented device, a globe stereothermometer, was used (Figure 2) [15, 16]. The globe temperature $t_{\mathrm{g}}$ was measured by this device as well.

A globe stereothermometer is a sphere with a diameter of $150 \mathrm{~mm}$ divided into six segments. This division has proved to be sufficient for practise. To investigate the most sensitive parts of the body - head, only five segments corresponding to the face, scalp, left, right and back of the head are necessary. More than six segments turned out to be redundant. The temperature of each segment is called a stereotemperature $t_{\text {stereo }}$ [17]. The modification patented by Jokl [18] lies in a division of the sphere thermometer's surface into six equal segments. The axes of segments are perpendicular to each other. The segments are thermally isolated from each other and are placed on a special internal design of a heat-insulating material. The internal structure ensures a separation of the heat conduction and also their mutual radiant influences. Based on the ability to distinguish among directions of the radiation and convection, the globe stereothermometer got its name.

The device is similar to a globe thermometer, which has been in a continuous use since 1923, and which 


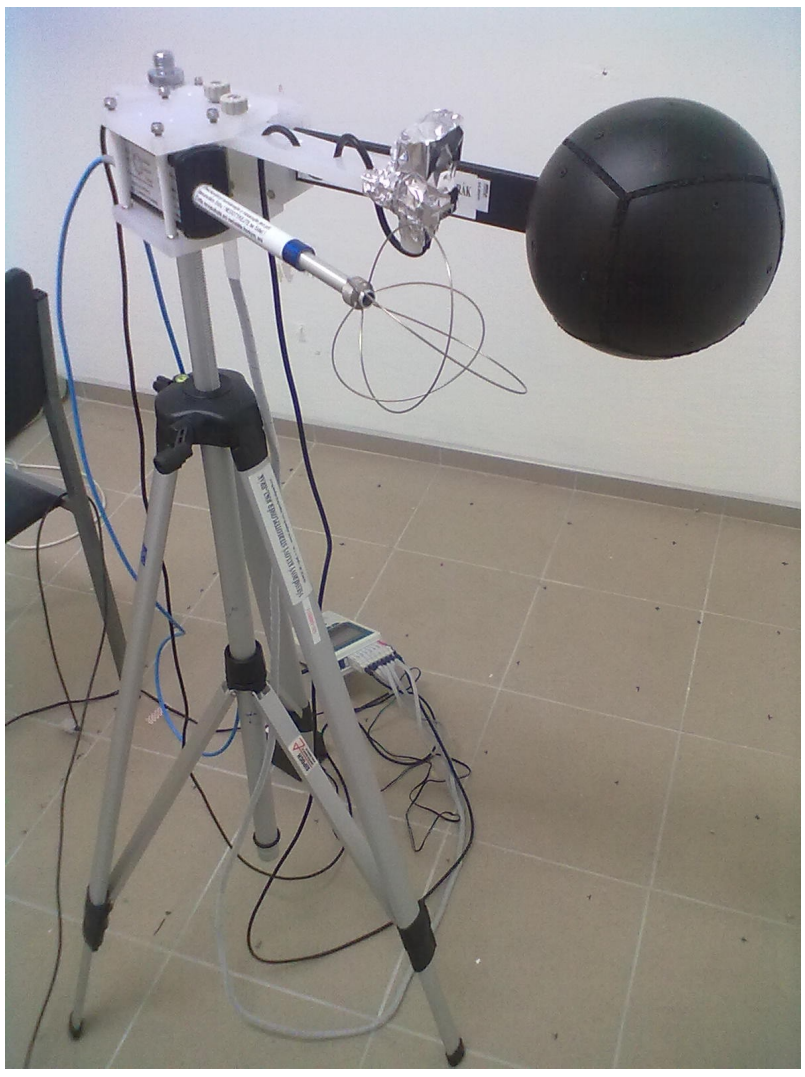

FIGURE 2. A globe stereothermometer and sensors for measuring the dry temperature and air velocity.

became a part of most state's standards and hygiene regulations. The globe thermometer does not represent a model of a human body, but it is a part of the equation of the heat balance; i.e., it can be used in the case of the globe temperature $t_{\mathrm{g}}$. The globe temperature of the globe thermometer $t_{\mathrm{g}}$ includes, however, only the effect of the air temperature and the effective radiation temperature, so that the criterion of the thermal comfort must be expressed in a relation to other factors contained in the heat balance equation of a human: air velocity and humidity, clothing, human activities, adaptation and time exposure [2].

Jokl, based on his research [18, 19], suggested an evaluation criterion for a non-uniform heat-humidity microclimate. This criterion corresponds to the difference between stereotemperature and the globe temperature of the globe stereothermometer:

$$
\Delta\left(t_{\text {stereo }}-t_{\mathrm{g}}\right) \quad \underset{\text { criterion: } t_{\mathrm{st}, \text { local }}-t_{\mathrm{g}, \text { mean }}}{\text { general }}
$$

(stereotemperature of exposed area minus stereotemperature of a whole).

\subsection{EтHICS}

The procedure of human experimentation was followed in an accordance with the ethical standards and the current laws of the Czech Republic and Helsinki declaration of 1964, as revised in 2013 [12].

\subsection{STATISTICS}

A correlation and regression analyses were used for the statistical evaluation $(\alpha=5 \%)$. Processing was done in Stata v. 9 [10].

\section{Results}

\subsection{Criterion validation "Heat load FROM THE SPACE $=f\left(t_{\text {stereo }}-t_{\mathrm{g}}\right)$ "}

The legitimacy of this relationship has to be proved in:

(1.) a physiological aspect of the correlation of the thermal environment with an average skin temperature;

(2.) a psychological aspect of the correlation of the thermal environment with human sensations.

The results of the correlation and regression analysis indicate the following.

(1.) from a physiological aspect, a very good correlation was found $(|R|=0.986)$ between the mean skin temperature $t_{\text {sk, average, and the relation of }}$ $\left(t_{\text {stereo }}-t_{\mathrm{g}}\right)$, where the thermal insulation of the clothing and the globe temperature were considered:

$$
\begin{aligned}
t_{\mathrm{sk}, \text { average }} & =23.452+1.294 I_{\mathrm{cl}} \\
+ & 0.361 t_{\mathrm{g}}-0.049\left(t_{\text {stereo }}-t_{\mathrm{g}}\right)\left[{ }^{\circ} \mathrm{C}\right],
\end{aligned}
$$

where $I_{\mathrm{cl}}$ is thermal insulation of clothing [clo]; $t_{\mathrm{g}}$ is the globe temperature $\left[{ }^{\circ} \mathrm{C}\right]$.

(2.) The European Standard EN ISO 7730 [6] was used. The seven-point scale of thermal sensations was used; see Table 2 (commonly accepted as a psychological representative of the heat load of a human). The experiment demonstrated a high correlation $(|R|=0.998)$ between $\left(t_{\text {stereo }}-t_{\mathrm{g}}\right)$ and thermal sensations (sensations) of subjects (Figure 3):

$$
\begin{array}{r}
\left(t_{\text {stereo }}-t_{\mathrm{g}}\right)=6.47 \text { sensations }-0.0824 t_{\mathrm{o}}^{2} \\
+2.967 t_{\mathrm{o}}-23.024\left[{ }^{\circ} \mathrm{C}\right],
\end{array}
$$

where $t_{\mathrm{o}}$ is the operative temperature, in conditions where $v_{\mathrm{a}} \leq 0.2 \mathrm{~m} \mathrm{~s}^{-1}$ we have $t_{\mathrm{o}}=t_{\mathrm{g}}\left[{ }^{\circ} \mathrm{C}\right]$; sensations is the thermal sensation, i.e., a subjective figure expressed in a seven-point scale -3 to +36 .

\subsection{RELATIONSHIP BETWEEN RADIANT TEMPERATURE ASYMMETRY AND STEREOTEMPERATURE}

The difference between stereotemperature and the globe temperature $\left(t_{\text {stereo }}-t_{\mathrm{g}}\right)$ was used instead of the radiant temperature difference. The relationship between the differences $\left(t_{\mathrm{rA}}-t_{\mathrm{rB}}\right)$ and $\left(t_{\text {stereo }}-t_{\mathrm{g}}\right)$ can be expressed by the equation by the following equation $(|R|=0.987)$ :

$$
\left(t_{\text {stereo }}-t_{\mathrm{g}}\right)=0.23\left(t_{\mathrm{rA}}-t_{\mathrm{rB}}\right)+0.2\left[{ }^{\circ} \mathrm{C}\right] ;
$$




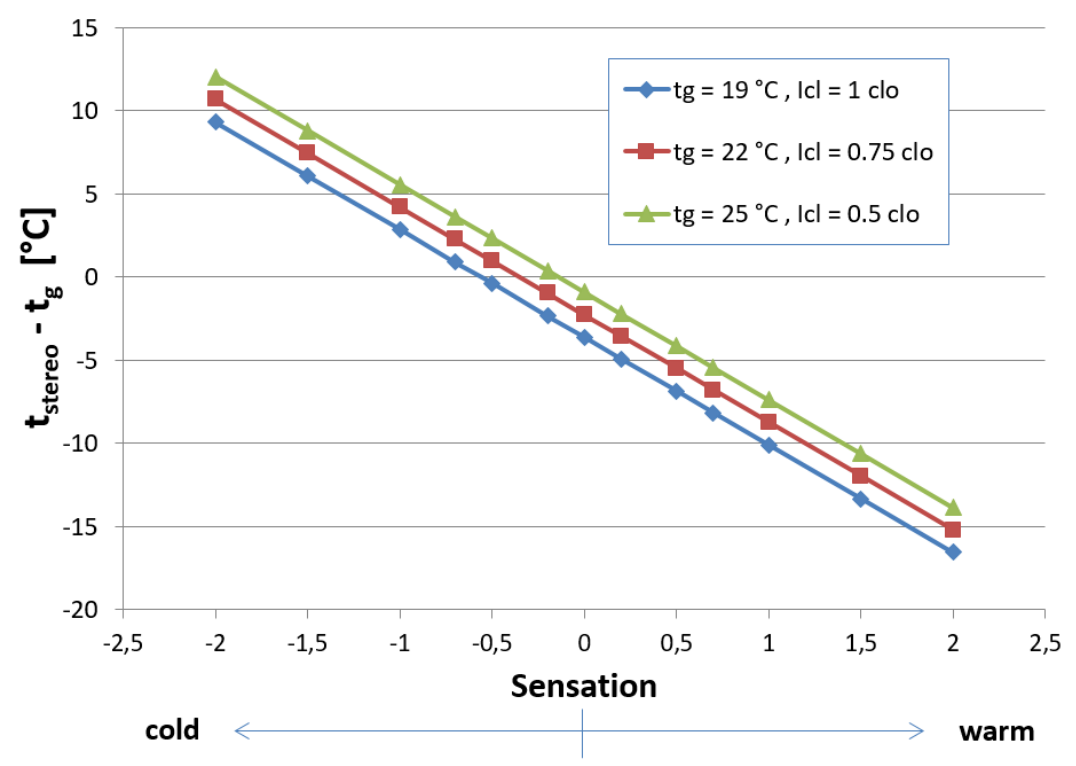

FigURE 3 . Correlation between $\left(t_{\text {stereo }}-t_{\mathrm{g}}\right)$ and thermal sensation of subjects expressed by the seven-point scale $(-3$ to +3$)$ depending on the globe temperature $\left(t_{\mathrm{g}}\right)$ and clothing insulation $\left(I_{\mathrm{cl}}\right)[20$.

\begin{tabular}{cc}
\hline Point scale & Sensation \\
\hline 3 & Hot \\
2 & Warm \\
1 & Slightly warm \\
0 & Neutral \\
-1 & Slightly cold \\
-2 & Cool \\
-3 & Cold \\
\hline
\end{tabular}

TABLE 2. The seven-point scale of thermal sensations 6].

the relationship is graphically illustrated in Figure 40

The stereotemperature correlated very well with $t_{\mathrm{rA}}$ $(|R|=0.989-0.994)$. Unlike $t_{\mathrm{rA}}, t_{\text {stereo }}$ also depends on the airflow. The relationship between $t_{\mathrm{rA}}$ and $t_{\text {stereo }}$ depending on the airflow in a range $0.25-1 \mathrm{~m} \mathrm{~s}^{-1}$ is shown in Figure 5

The results of the experiments expressing the relationship (4) between $\left(t_{\text {stereo }}-t_{\mathrm{g}}\right)$ and the feeling of warmth of subjects were used to design tables of allowable values of a non-uniform radiant-convective load for low demanding job working classes I and IIa to the amended Government Regulation No. 93/2012 Coll. 9] (see Tables 3 and 4). Working classes I and Ila include occupations, such as PC workers, management, administrative work, lab workers, cashiers and car drivers. Furthermore, in an accordance with EN ISO 7730 [6] to the sanitary regulations, the limits for workplaces with high demands on the thermal comfort environment (workplace categories A and B) and workplaces with common requirements for the thermal comfort environment (category C) were established.
Category A and B are used for offices with the required high and medium quality of an environment (sensation of warmth in the range of \pm 0.5 ). The category $\mathrm{C}$ is used for other workplaces with common demands on the quality of the environment (a sensation of warmth in the range of \pm 0.7 ) [6].

\section{Discussion}

One of the aims of the experiment was to determine the response of the selected physiological parameters and subjective feelings of experimental subjects (ES) during mental work in a non-uniform radiantconvective load under experimental conditions in a climatic chamber. But, it is necessary to consider that the experiment would have a higher perceptive value with a higher number of people and a more diverse group - gender and age. In this case, women were chosen because of their higher sensitivity to microclimatic conditions 21. Due to the fact that the experiments were carried out on ESs seated during mental work, the results cannot be applied to intense human activities. The results are used as a basis for adjusting level I and IIa work classes in the Czech regulation for the protection of health at work.

Another objective was to verify the applicability of $\Delta\left(t_{\text {stereo }}-t_{\mathrm{g}}\right)$, which was introduced into Czech legislation "Health Protection at Work". The proposed criterion has a distinct advantage - the effects of convection. It is necessary to understand the implications of the standards (meaning primarily EN ISO 7730), that the allowable values of the radiant temperature asymmetry (RTA) could be achieved by an intensity radiation reduction of the given surface (if possible), or by increasing the intensity of the radiation from 


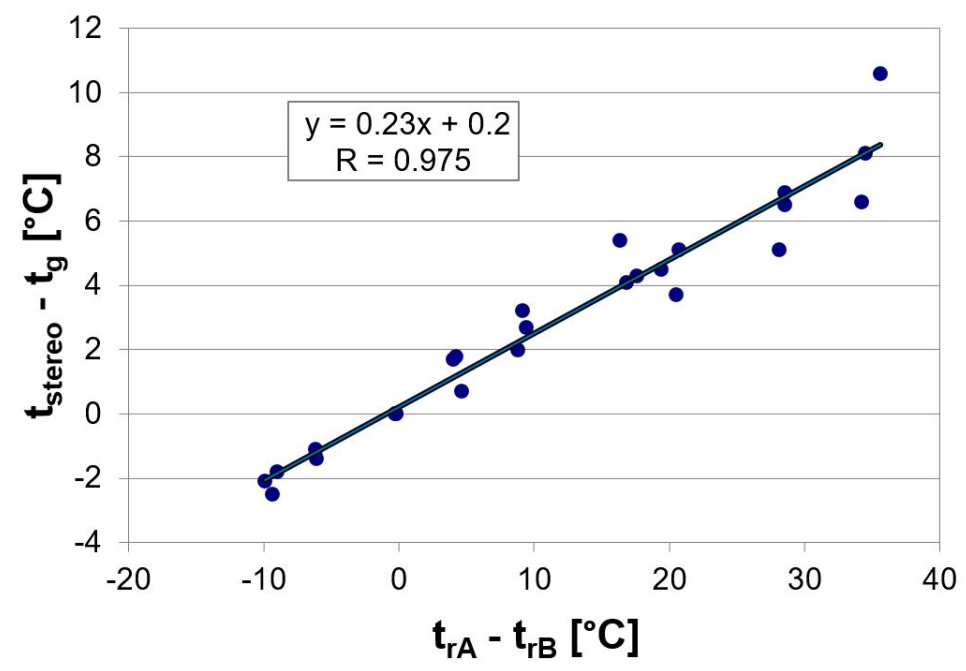

FigURE 4. Relationship between the temperature differences $\left(t_{\text {stereo }}-t_{\mathrm{g}}\right)$ and $\left(t_{\mathrm{rA}}-t_{\mathrm{rB}}\right)$ calculated from all measurements $\left(v_{\mathrm{a}}=0.25-1.0 \mathrm{~m} \mathrm{~s}^{-1}\right)[20$.

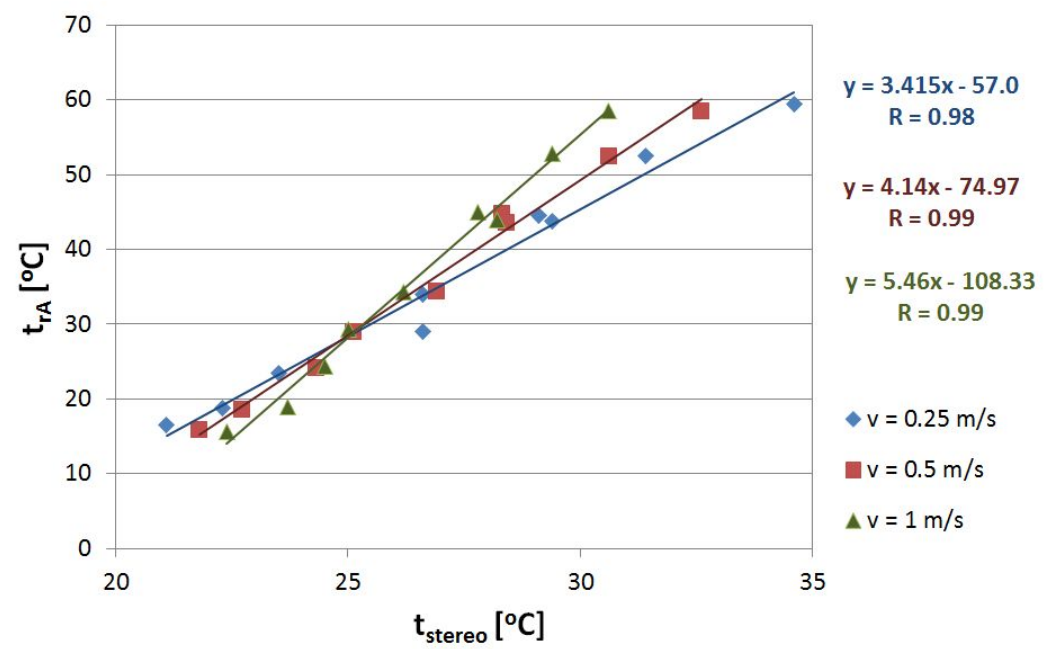

FiguRE 5. The relationship between radiant temperature $t_{\mathrm{rA}}$ and stereotemperature $t_{\text {stereo }}$ depending on the air flow $v_{\mathrm{a}}=0.25--1 \mathrm{~m} \mathrm{~s}^{-1} 20$.

the opposite side. In these two options, the convection is not included in the RTA, despite it being an important factor. For example, if we compensate a high radiation from one side by a cool air via an air conditioner from the same side, asymmetry of the temperature would not change because of the convection. The discrepancy is caused by the assumption that the radiation of an exposed surface of the body is also dependent on the radiation from the opposite unexposed surface of the human body. The radiation of each side needs to be solved separately. In terms of physiology, the radiation of one side cannot be solved by the intervention on the opposite surface of the body. From the foregoing, it is evident that the radiant intensity is not suitable as well. These criteria should be replaced by a criterion that includes a radiation of exposed side and also contains the convection.

Disadvantages of this study might be in measuring the stereotemperature only at $1.1 \mathrm{~m}$ above the floor and with a low air velocity. Further studies in more varied conditions are necessary. Two objective methods of microclimate evaluation were also compared in the study, particularly its non-uniform radiantconvective components. The relationship (5) and the dependence in Figure 5 show that a globe thermometer can be used to measure the radiant temperature asymmetry and recalculate the value of the difference of the plane radiant temperature. The comparison in Tables 3 and 4 show that the difference between stereotemperature $t_{\text {stereo }}$ and the globe temperature 


\begin{tabular}{|c|c|c|c|c|c|c|}
\hline \multirow{3}{*}{$\begin{array}{c}t_{g} \text { on the } \\
\text { level } \\
\text { of head } \\
{\left[{ }^{\circ} \mathrm{C}\right]}\end{array}$} & \multicolumn{6}{|c|}{ To cold surface } \\
\hline & \multicolumn{3}{|c|}{ category A, B } & \multicolumn{3}{|c|}{ category $\mathrm{C}$} \\
\hline & $\begin{array}{c}t_{\text {stereo }} \\
{\left[{ }^{\circ} \mathrm{C}\right]}\end{array}$ & $\begin{array}{c}\Delta\left(t_{\text {stereo }}-t_{\mathrm{g}}\right) \\
{\left[{ }^{\circ} \mathrm{C}\right]}\end{array}$ & $\begin{array}{c}\text { ISO } t_{\mathrm{rA}}-t_{\mathrm{rB}} \\
{\left[{ }^{\circ} \mathrm{C}\right]}\end{array}$ & $\begin{array}{c}t_{\text {stereo }} \\
{\left[{ }^{\circ} \mathrm{C}\right]}\end{array}$ & $\begin{array}{c}\Delta\left(t_{\text {stereo }}-t_{\mathrm{g}}\right) \\
{\left[{ }^{\circ} \mathrm{C}\right]}\end{array}$ & $\begin{array}{c}\text { ISO } t_{\mathrm{rA}}-t_{\mathrm{rB}} \\
{\left[{ }^{\circ} \mathrm{C}\right]}\end{array}$ \\
\hline 20 & 20.0 & 0 & & 18.8 & -1.2 & \\
\hline 21 & 20.7 & -0.3 & & 19.4 & -1.6 & \\
\hline 22 & 21.1 & -0.9 & & 19.8 & -2.2 & \\
\hline 23 & 21.4 & -1.6 & 21 & 20.1 & -2.9 & \\
\hline 24 & 21.5 & -2.5 & 2.1 & 20.2 & -3.8 & 2.7 \\
\hline 25 & 21.4 & -3.6 & & 20.1 & -4.9 & \\
\hline 26 & 21.2 & -4.8 & & 19.9 & -6.1 & \\
\hline 27 & 20.8 & -6.2 & & 19.5 & -7.5 & \\
\hline
\end{tabular}

TABLE 3. Allowable horizontal differences $\Delta\left(t_{\text {stereo }}-t_{\mathrm{g}}\right)$ between the stereotemperature and the globe temperature at the head level in the case of standard working classes I and IIa performed at workplaces inside buildings 9 .

\begin{tabular}{|c|c|c|c|c|c|c|}
\hline \multirow{3}{*}{$\begin{array}{c}t_{g} \text { on the } \\
\text { level } \\
\text { of head } \\
{\left[{ }^{\circ} \mathrm{C}\right]}\end{array}$} & \multicolumn{6}{|c|}{ To warm surface } \\
\hline & \multicolumn{3}{|c|}{ category A, B } & \multicolumn{3}{|c|}{ category $\mathrm{C}$} \\
\hline & $\begin{array}{c}t_{\text {stereo }} \\
{\left[{ }^{\circ} \mathrm{C}\right]}\end{array}$ & $\begin{array}{c}\Delta\left(t_{\text {stereo }}-t_{\mathrm{g}}\right) \\
{\left[{ }^{\circ} \mathrm{C}\right]}\end{array}$ & $\begin{array}{c}\text { ISO } t_{\mathrm{rA}}-t_{\mathrm{rB}} \\
{\left[{ }^{\circ} \mathrm{C}\right]}\end{array}$ & $\begin{array}{l}t_{\text {stereo }} \\
{\left[{ }^{\circ} \mathrm{C}\right]}\end{array}$ & $\begin{array}{c}\Delta\left(t_{\text {stereo }}-t_{\mathrm{g}}\right) \\
{\left[{ }^{\circ} \mathrm{C}\right]}\end{array}$ & $\begin{array}{c}\text { ISO } t_{\mathrm{rA}}-t_{\mathrm{rB}} \\
{\left[{ }^{\circ} \mathrm{C}\right]}\end{array}$ \\
\hline 20 & 26.6 & 6.6 & \multirow{8}{*}{4.9} & 27.9 & 7.9 & \multirow{8}{*}{7.5} \\
\hline 21 & 27.2 & 6.2 & & 28.5 & 7.5 & \\
\hline 22 & 27.6 & 5.6 & & 28.9 & 6.9 & \\
\hline 23 & 27.9 & 4.9 & & 29.2 & 6.2 & \\
\hline 24 & 28.0 & 4.0 & & 29.3 & 5.3 & \\
\hline 25 & 27.9 & 2.9 & & 29.2 & 4.2 & \\
\hline 26 & 27.7 & 1.7 & & 28.9 & 2.9 & \\
\hline 27 & 27.3 & 0.7 & & 28.5 & 1.5 & \\
\hline
\end{tabular}

TABLE 4. Allowable horizontal differences $\Delta\left(t_{\text {stereo }}-t_{\mathrm{g}}\right)$ between the stereotemperature and the globe temperature at the head level in the case of standard working classes I and IIa performed at workplaces inside buildings 9 .

$t_{\mathrm{g}}$ at the level of head reflects more of the required differences changing in a relatively wide range, i.e., max. and min. limits that must be met from the hygienic point of view.

The globe stereothermometer was used for an evaluation of the non-uniformity microclimate conditions. It was based on the contention [18 that the globe stereothermometer includes the combined effect of the radiation and convection allowing evaluating an omnidirectional radiation exposure and is able to measure the difference between stereotemperatures.

\section{Conclusions}

The work has proved that stereotemperature shows the effect of the thermal radiation and convection; i.e., the heat flow depended on the ambient airflow, the humidity and the temperature differences. It has been shown that the value of $\Delta\left(t_{\text {stereo }}-t_{\mathrm{g}}\right)$ characterizes the inequality of the thermal environment, as well as the value of $\Delta\left(t_{\mathrm{rA}}-t_{\mathrm{rB}}\right)$ does. The advantage of using a stereothermometer in practice is that it allows a simultaneous continuous measurement of both the globe temperature and the radiant temperature on its six sides.
By adding the stereotemperature to Government Regulation No. 93/2012 Coll., "Health Protection at Work", it is possible to more accurately measure the perception of the climate conditions of exposed workers. The values obtained from the experiments were used to design tables of allowable values for low demanding work classes I and II, which require mental work. In accordance with EN ISO 7730, limits were designed differently for workplaces with high demands on the thermal comfort environment (workplace categories A and B) and work with common requirements for the thermal comfort environment (category C).

\section{ACKNOWLEDGEMENTS}

The work presents the results of the project "Working comfort and reliability of man in the working system" in research of VÚBP identification code: MPS0002595001: "BOZP - source of quality of life, work and business culture" and this work was supported by the Grant Agency of the Czech Technical University in Prague, grant No. SGS16/017/OHK1/1T/11.

I would like to express my appreciation to Professor Miloslav V. Jokl (CTU in Prague) and Professor Zdeněk Jirák (University of Ostrava) for helpful basics, comments and advices for this manuscript. 


\section{LIST OF SYMBOLS}

$P M V$ Predicted mean vote. The predicted mean vote of a group of people on the 7-point thermal sensation scale.

$P P D$ Predicted percentage of dissatisfied. The predicted percentage of a group of people who are feeling too cold or too hot. [\%]

$R T A$ radiant temperature asymmetry

$t_{\text {stereo }}, t_{\text {st }}$ stereotemperature $\left[{ }^{\circ} \mathrm{C}\right]$

$t_{\mathrm{g}}$ globe temperature $\left[{ }^{\circ} \mathrm{C}\right]$

$t_{\mathrm{rA}}$ radiant temperature (measured from the direction of radiation $\mathrm{A})\left[{ }^{\circ} \mathrm{C}\right]$

$t_{\mathrm{rB}}$ radiant temperature (measured from the direction of radiation $\mathrm{B})\left[{ }^{\circ} \mathrm{C}\right]$

$v_{\mathrm{a}}$ air velocity $\left[\mathrm{ms}^{-1}\right]$

$t_{\mathrm{a}}$ air temperature $\left[{ }^{\circ} \mathrm{C}\right]$

RH relative humidity [\%]

$t_{\mathrm{pr}(1,2)}$ plane radiant temperature (direction 1 or 2 ) $\left[{ }^{\circ} \mathrm{C}\right]$

$I$ radiation intensity $\left[\mathrm{W} \mathrm{m}^{-2}\right]$

$t_{\mathrm{o}}$ operative temperature $\left[{ }^{\circ} \mathrm{C}\right]$

$I_{\mathrm{cl}}$ clothing insulation $\left[\mathrm{W} \mathrm{m}^{-2}\right]$

$t_{\text {sk }}$ skin temperature $\left[{ }^{\circ} \mathrm{C}\right]$

$t_{\text {sk,average }}$ mean skin temperature $\left[{ }^{\circ} \mathrm{C}\right]$

\section{REFERENCES}

[1] D. A. McIntyre. Indoor climate. Applied Science Publishers, London, 1980.

[2] P. O. Fanger, et al. Comfort limits for heated ceilings. ASHRAE Trans 86(2):141-146, 1980.

[3] P. M. Bluysenn. The indoor environment handbook: How to make buildings healthy and comfortable. London: Earthscan, 2009. DOI:10.4324/9781849774611

[4] D. Kalibatas, E. K. Zavadskas. Multiple criteria analysis of indoor climate at the workplace. Proceedings of the 9th International Conference Modern Building Materials, Structures and Techniques. Vilnius, Lithuania, 2007. http://www.vgtu.lt/leidiniai/leidykla/MBM_ 2007/2pdf/Kalibatas_Zavadskas.pdf [2016-02-25].

[5] L. Centnerova. Tradiční \& adaptabilni model tepelné pohody [Traditional and Adaptive Thermal Comfort] Ph.D. thesis. Czech Technical University, Prague 2001 [in Czech].

[6] EN ISO 7730:2005. Ergonomics of the Thermal Environment - Analytical Determination and Interpretation of Thermal Comfort Using Calculation of the PMV and PPD Indices and Local Thermal Comfort Criteria, 2005.

[7] P. O. Fanger. Thermal Comfort. McGraw-Hill, New York, 1972.

[8] M. A. Humphreys, J. F. Nicol. The validity of ISO-PMV for predicting comfort votes in everyday thermal environment. Energy and Build 34:667-684, 2002. DOI:10.1016/s0378-7788(02)00018-x

[9] [Government Regulation No. 93/2012 Coll., changing the Government Regulation No. 361/2007 Coll. prescribing the conditions for employees protection during the work, as amended by Government Directive No. 68/2010 Coll.] Collection of laws of the Czech Republic [in Czech].
[10] STATA Statistical software: Release 9.0 College Station, TX: Stata Corporation, 2005.

[11] EN ISO 9920. Ergonomics of the Thermal Environment - Estimation of Thermal Insulation and Water Vapour Resistance of a Clothing Ensemble, 2009.

[12] Declaration of Helsinki. 2013. World Medical Declaration of Helsinki: Ethical Principles for Medical Research Involving Human Subjects. https://www.wma.net/policies-post/wmadeclaration-of-helsinki-ethical-principles-formedical-research-involving-human-subjects/ [2017-10-25].

[13] S. Bernatikova, Z. Jirak and S. Maly. [Influence of irregular radiation-convection heat stress on the reliability performance of the human factor]. Collection of scientific works of the VSB - Technical University of Ostrava. 5(2):13-22, 2010. [in Czech].

[14] EN ISO 7726:2002. Ergonomics of the Thermal Environment - Instruments for Measurements of Physical Quantities, 2002.

[15] Z. Oleksiakova, et al. Globe Stereothermometer - A new instrument for measurement and evaluation of irregular radiant-convective load. Advances in Human Factors and Ergonomics Series, 521-530, 2010. DOI:10.1201/ebk1439834992-54

[16] Z. Jirak, et al. [Response of psychological indices to irregular radiation load in experimental conditions of climatic chamber]. Czech J Occup Med 17(4):125-130, 2008 [in Czech].

[17] M. V. Jokl. The stereothermometer: A new instrument for hygrothermal constituent non-uniformity evaluation. ASHRAE Trans 97(1):13-18, 1991.

[18] M. V. Jokl. Hygrothermal microclimate: New System for Evaluation of Non-uniformity. Build Serv Eng Res Technol 13(4):225-230, 1992. DOI:10.1177/014362449201300406

[19] M. V. Jokl, K. Kabele and F. Jordan. A methodology for the comprehensive evaluation of the indoor climate based on human body response, Part 2.1: Hygrothermal microclimate evaluation based on human physiology. ASHRAE Trans 117(1):806-816, 2011. DOI:10.1016/j.enbuild.2014.09.061

[20] Z. Jirak, et al. [A new approach to the evaluation of heat-humidity conditions in the workplace]. Czech $J$ Occup Med 64(1):23-31, 2012 [in Czech].

[21] Bortkiewicz, A. et al. Physiological Reaction to Work in Cold Microclimate. Int J of Occup Med and Env Health 19(2), 2006. DOI:10.2478/v10001-006-0020-y 